\title{
Bowel endometriosis: a surgical red flag
}

\section{Ketan Vagholkar*, Arpit Murarka, Sandeeta Shetty, Suvarna Vagholkar}

Department of Surgery, D. Y. Patil University School of Medicine, Navi Mumbai, Maharashtra, India

Received: 17 August 2017

Accepted: 21 August 2017

\section{*Correspondence:}

Dr. Ketan Vagholkar,

E-mail: kvagholkar@yahoo.com

Copyright: (c) the author(s), publisher and licensee Medip Academy. This is an open-access article distributed under the terms of the Creative Commons Attribution Non-Commercial License, which permits unrestricted non-commercial use, distribution, and reproduction in any medium, provided the original work is properly cited.

\section{ABSTRACT}

Endometriosis is a disease restricted usually to the female genital tract. Involvement of the bowel by this disease can lead to a diagnostic dilemma due to the great variation in the symptomatology. Awareness of the pathophysiology, clinical features and diagnostic modalities is of utmost importance to decide the modality of treatment. Hormonal manipulation and surgical resection are the two modalities of treatment. The choice depends upon critical analysis of clinical and radiological findings and the desire to have pregnancy in cases associated with infertility.

Keywords: Bowel endometriosis, Medical surgical management

\section{INTRODUCTION}

$4 \%-17 \%$ of women during their active reproductive age suffer from endometriosis. ${ }^{1,2}$ Out of these $5 \%-10 \%$ of women have colorectal involvement. ${ }^{2}$ The symptoms of bowel endometriosis closely simulates intrinsic bowel disease making diagnosis very difficult. ${ }^{3,4}$ Hence awareness of this complex entity is essential to avoid misdiagnosis and unnecessary surgical intervention.

\section{Pathophysiology}

Various theories have been proposed for the etiology of endometriosis. The hypothesis of retrograde menstruation with seeding of endometrial tissue into the peritoneal cavity through the fallopian tube is most commonly accepted. These endometrial implants may settle down in the most dependent areas of the pelvic cavity. ${ }^{5}$ Therefore, the rectouterine pouch of Douglas happens to be the commonest site for endometriotic deposits. This is followed by ovarian deposits.

Symptoms of endometriosis at these sites may be easy to analyze in order to arrive at a diagnosis. However, in addition to these common sites, seeding of the sigmoid colon, rectum, ileum, appendix and caecum is encountered. ${ }^{5,6}$ Endometriotic deposits grow over a period of time under the influence of hormonal stimulation. These deposits slowly invade the bowel wall. To start with they are deposited on the serosal surface but with time may cross the muscularis layer.

Mucosal involvement is quite uncommon. However, in the pouch of Douglas they cause dense adhesions between the recto-sigmoid junction, rectum and the posterior uterine wall. ${ }^{6}$ Deposits on the appendix, ileum or the caecum may closely mimic appendicitis.

As the disease progresses the lesions caused damage to the intrinsic nerve plexus of the intestine, interstitial Cajal cells as well as cause a decrease in the functioning of the sympathetic nerve fibres. ${ }^{3,4}$ Eventually these changes cause a gross alteration in the bowel physiology.

Grossly pigmented nodules are seen on the peritoneal surface of the bowel with typical puckering of the serosa. (Figure 1) This in many cases is indistinguishable from carcinoma. ${ }^{6,7}$ Submucosal involvement may commonly be encountered in advanced cases. (Figure 2) However mucosal involvement is quite rare. 


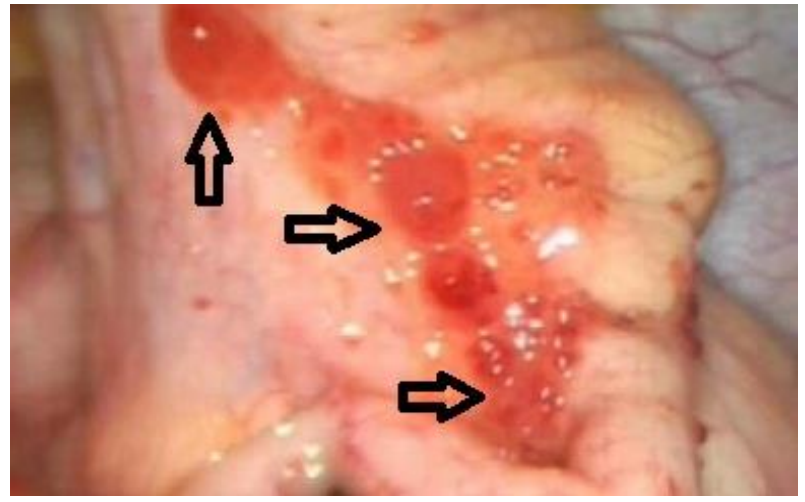

Figure 1: Endometriotic nodules on the surface of the caecum.

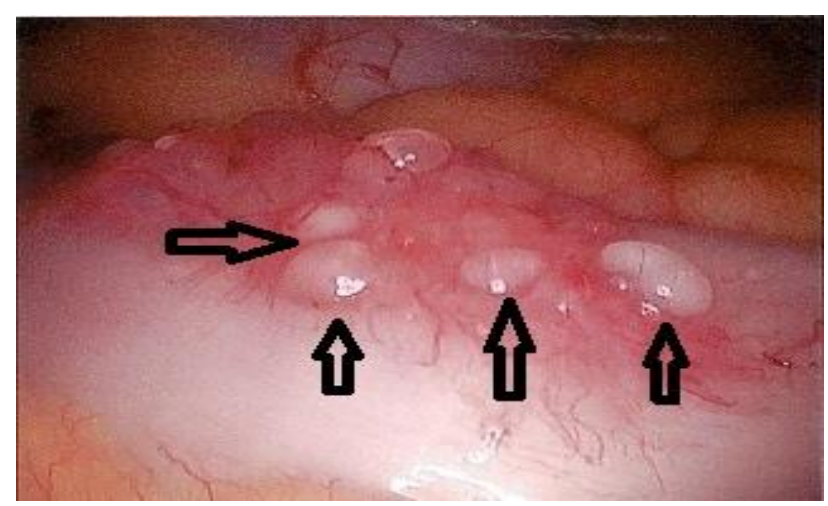

Figure 2: Endometriotic nodules over the bowel surface.

\section{Clinical features}

Pelvic pain, dyspareunia, cyclical rectal bleeding associated with the menstrual cycle are the commonest presenting features. However, bowel symptoms associated with menstrual cycle are commonly misinterpreted. ${ }^{6,7}$ Symptoms like severe excruciating pain associated with obstructive symptoms are commonly encountered in severe cases. Otherwise, diarrhea like disease may also be encountered. These features are commonly attributed to inflammatory bowel disease and therefore wrongly treated. Therefore, careful analysis of symptoms and their close relationship with the events taking place during the menstrual cycle are essential in arriving at an early diagnosis.

\section{Diagnosis}

Critical analysis of symptoms will lead to a presumptive diagnosis of bowel endometriosis. Many of these women will be undergoing treatment for infertility which is additional evidence in support of the diagnosis. However, imaging is necessary to confirm the diagnosis. Traditional barium studies can still be performed. However, they have been replaced by other modern modalities of imaging. Trans-Vaginal Ultrasound (TVU) is a very effective method of diagnosing endometriosis. ${ }^{8-10}$
However the diagnostic accuracy of ultrasonography depends on the experience of the operator. Adding water contrast to the rectum during transvaginal ultrasonography may facilitate identification of bowel endometriotic lesions. It will also help in evaluation of the extent and severity of the disease. This includes size of the nodules, number of nodules, depth of infiltration in the bowel wall and degree of narrowing caused by the lesion. This can only be possible if adequate bowel preparation has been done prior to the procedure. ${ }^{8,9}$

MRI Is another investigation which has high sensitivity and specificity. Injection of ultrasonography gel into the vagina and the rectum prior to an MRI is proposed to enhance the identification of bowel lesions. ${ }^{11}$

Multidetector computerized tomographic enteroclysis (MDCT-e) has in recent years proven to become the diagnostic investigation for bowel endometriosis. ${ }^{11,12}$ After adequate bowel preparation, colonic distension is done by introducing about 2000cc of water. During enteroclysis, pharmacologic inhibition of peristaltic waves is achieved by intravenous injection of hyoscine butyl bromide.

Patient is examined with a 16 row MDCT scanner. Bowel endometriosis with respect to characteristics of nodules is very well identified. The depth of infiltration can also be very well assessed. This investigation has become the gold standard for diagnosis of bowel endometriosis. ${ }^{12,13}$ Rectal endoscopic ultrasound is also performed. This also helps in precise evaluation of the depth of infiltration of the lesion, Maximum size of the lesions and the distance of the lesions from the anus. Colonoscopy has limited value and his helpful only in ruling out malignant bowel cancers.

\section{Treatment}

The choice of treatment depends upon the age of the patient, parity, endocrine status and the extent of the disease. If Infertility is an accompaniment then the attitude of the patient towards child bearing is also an important determinant.

\section{Hormonal manipulation}

Those patients with bowel endometriosis who wish to conceive are not good patients for hormonal manipulation. ${ }^{14,15}$ Hormonal manipulation alleviates the pain and discomfort but does not halt the progression of the disease. Therefore, it is a temporary avail for patients. Combination pills (Estrogen-Progesterone Oral Contraceptive Pills) are medications of choice to alleviate symptoms. However, prolonged use of these medications can cause a variety of other complications. Inducing a pseudo-menopause like state by administering danozole or gonadotropin releasing hormone agonist is another way of alleviating symptoms. GnRH agonists like leuprolide acetate is quite effective in case of bowel 
endometriosis. ${ }^{15,16}$ The duration of treatment extends from 3-6 months.

\section{Surgical treatment}

Severe pain and infertility are indications for surgical intervention. A variety of surgical modalities have been proposed. Laparoscopic removal of nodules is a commonly performed surgical intervention. However, when severe adhesions lead to stenosis and obstruction, open surgical intervention remains the treatment of choice. It is always a safe practice to adequately prepare the bowel prior to surgical intervention. ${ }^{17-19}$ This allows safe resection of affected segments of the bowel. Superficial nodulectomy is also effective in ameliorating symptoms. In many cases a combination of nodulectomy with resection may be required. This is especially seen in endometriotic deposits over the rectum and recto-sigmoid region with accompanying extensive adhesions with the uterus. In patients presenting with large masses, especially on the left side with involvement of the rectosigmoid junction, bowel resection and left sided salpingo-oophorectomy may be carried out. However, the opposite side tube and ovary needs to be preserved if the patient is young and desirous of having a pregnancy. Mobilization of the left colon is necessary to reduce the tension on the anastomosis especially while resecting recto-sigmoid lesions.

\section{Impact of surgery on fertility}

A meticulously performed surgical resection will not affect the fertility adversely. Studies have shown a $50 \%$ pregnancy rate after laparoscopic colorectal resection. ${ }^{19,20}$ Another study has shown an $84 \%$ pregnancy rate after nodulectomy. ${ }^{21,22}$ A higher pregnancy rate after surgical intervention can be explained on the basis of an unaltered female hormonal homeostasis.

\section{CONCLUSION}

Bowel endometriosis is a challenging clinical disease. It poses a diagnostic dilemma to both the gynecologist as well as to the surgeon. High index of suspicion based on a good clinical history is pivotal. Trans-vaginal ultrasound (TVU) followed by MDCT-e will confirm the diagnosis. Choice between hormonal treatment and surgical treatment will be determined by various factors with the attitude towards pregnancy being given utmost importance.

\section{ACKNOWLEDGMENTS}

The authors would like to thank Mr. Parth K. Vagholkar for his help in typesetting the manuscript.

Funding: No funding sources Conflict of interest: None declared Ethical approval: Not required

\section{REFERENCES}

1. Bianchi A, Pulido L, Espín F, Hidalgo LA, Heredia A, Fantova MJ et al. Intestinal endometriosis. Current status Cir Esp. 2007;81:170-6.

2. Chapron C, Chopin N, Borghese B, Foulot H, Dousset B, Vacher-Lavenu MC et al. Deeply infiltrating endometriosis: pathogenetic implications of the anatomical distribution. Hum Reprod. 2006;21:1839-45.

3. Remorgida V, Ragni N, Ferrero S, Anserini P, Torelli P, Fulcheri E. The involvement of the interstitial Cajal cells and the enteric nervous system in bowel endometriosis. Hum Reprod. 2000;20:264271.

4. Ferrero S, Haas S, Remorgida V, Camerini G, Fulcheri E, Ragni $\mathrm{N}$ et al. Loss of sympathetic nerve fibers in intestinal endometriosis. Fertil Steril. 2010;94:2817-9.

5. Yantiss RK, Clement PB, Young RH. Endometriosis of the intestinal tract: a study of 44 cases of a disease that may cause diverse challenges in clinical and pathologic evaluation. Am J Surg Pathol. 2001;25:445-454.

6. Jenkins S, Olive DL, Haney AF. Endometriosis:pathogenetic implications of the anatomic distribution. Obstet Gynecol. 1986;67:33538.

7. Chapron C, Fauconnier A, Vieira M, Barakat H, Dousset B, Pansini V et al. Anatomical distribution of deeply infiltrating endometriosis: surgical implications and proposition for a classification. Hum Reprod. 2003;18:157-161.

8. Hudelist G, English J, Thomas AE, Tinelli A, Singer $\mathrm{CF}$, Keckstein J. Diagnostic accuracy of transvaginal ultrasound for non-invasive diagnosis of bowel endometriosis: systematic review and meta-analysis. Ultrasound Obstet Gynecol. 2011;37:257-263.

9. Abrao MS, Gonçalves MO, Dias JA Jr, Podgaec S, Chamie LP, Blasbalg R. Comparison between clinical examination, transvaginal sonography and magnetic resonance imaging for the diagnosis of deep endometriosis. Hum Reprod. 2007;22:3092-7.

10. Goncalves MO, Podgaec S, Dias JA Jr, Gonzalez M, Abrao MS. Transvaginal ultrasonography with bowel preparation is able to predict the number of lesions and rectosigmoid layers affected in cases of deep endometriosis, defining surgical strategy. Hum Reprod. 2010;25:660-671.

11. Bazot M, Darai E, Hourani R, Thomassin I, Cortez A, Uzan $S$ et al. Deep pelvic endometriosis: MR imaging for diagnosis and prediction of extension of disease. Radiology. 2004;232:379-89.

12. Remorgida V, Ferrero S, Fulcheri E, Ragni N, Martin DC. Bowel endometriosis: presentation, diagnosis, and treatment. Obstet Gynecol Surv. 2007;62:461-470.

13. Ferrero S, Abbamonte LH, Remorgida V, Ragni N. Irritable bowel syndrome and endometriosis. Eur $\mathbf{J}$ Gastroenterol Hepatol. 2005;17:687. 
14. Ferrero S, Remorgida V, Venturini PL. Current pharmacotherapy for endometriosis. Expert Opin Pharmacother. 2010;11:1123-34.

15. Porpora MG, Pallante D, Ferro A, Crobu M, Cerenzia P, Panici PL. Intestinal endometriosis without evident pelvic foci treated with gonadotropin-releasing hormone agonist. Eur J Obstet Gynecol Reprod Biol. 2006;125:260-6.

16. Ferrero S, Camerini G, Ragni N, Venturini PL, Biscaldi E, Seracchioli $\mathrm{R}$ et al. Letrozole and norethisterone acetate in colorectal endometriosis. Eur J Obstet Gynecol Reprod Biol. 2010;150:199202.

17. Vagholkar KR. Healing of anastomoses in the gastrointestinal tract. (Retrospective study of 35 cases). Bombay Hospital J. 2001;43(2):269-279.

18. Vagholkar KR. Postoperative adhesive intestinal obstruction. Bombay Hospital J. 1996;38(2):365-9.

19. Daraï E, Bazot M, Rouzier R, Houry S, Dubernard G. Outcome of laparoscopic colorectal resection for endometriosis. Curr Opin Obstet Gynecol. 2007;19:308-313.
20. Daraï E, Marpeau O, Thomassin I, Dubernard G, Barranger E, Bazot M. Fertility after laparoscopic colorectal resection for endometriosis: preliminary results. Fertil Steril. 2005;84:945-950.

21. Ferrero S, Anserini P, Abbamonte LH, Ragni N, Camerini G, Remorgida V. Fertility after bowel resection for endometriosis. Fertil Steril. 2009;92:416.

22. Donnez J, Squifflet J. Complications, pregnancy and recurrence in a prospective series of 500 patients operated on by the shaving technique for deep rectovaginal endometriotic nodules. Hum Reprod 2010;25:1949-58.

Cite this article as: Vagholkar K, Murarka A, Shetty S, Vagholkar S. Bowel endometriosis: a surgical red flag. Int J Reprod Contracept Obstet Gynecol 2017;6:4193-6. 